\title{
Prime detection of Dirofilaria immitis: understanding the influence of blocked antigen on heartworm test performance
}

\author{
Susan Little*, Meriam Saleh, Megan Wohltjen and Yoko Nagamori
}

\begin{abstract}
Detection of circulating antigen of Dirofilaria immitis has been a mainstay of identifying heartworm infection in clinical practice for the past three decades. Several validated commercial antigen tests have very good sensitivity, specificity, and positive predictive values, especially when used in patients for which heartworm infection is likely. In some dogs and cats infected with heartworm, antigen may not be available for detection although present in the patient sample; heat pretreatment of these samples reveals the antigen, changing the false negative to positive. This phenomenon was documented in the literature in the 1980s but subsequently overlooked by the heartworm research community for many years. In this review, we provide a summary of the current understanding of the role of heat reversal in diagnosing heartworm infection. This additional diagnostic step is most important for patients in which heartworm infection is likely, such as dogs or cats in an endemic area with an inconsistent history of heartworm preventive use, or dogs with a prior diagnosis of heartworm infection that were recently treated. To illustrate the concept, we share a summary of results from canine samples tested at the state veterinary diagnostic laboratory in Oklahoma, USA in 2017 by modified Knott test and by commercial antigen test before and after heat treatment of samples; in this sample set, heat treatment changed all D. immitis microfilaria-positive but antigennegative samples to antigen-positive. Pet dogs with a history of consistent preventive use are unlikely to become positive with heat pretreatment; for that reason, routine pretreatment of all samples tested in a veterinary practice is not recommended. We also review known causes of false negative and false positive results on heartworm antigen tests that, although uncommon, can complicate accurate diagnosis in individual patients. Together, this review provides a primer to aid understanding of strategies that can enhance accurate diagnosis of heartworm infection in veterinary practice and clinical research.
\end{abstract}

Keywords: Antigen, Diagnosis, Dirofilaria immitis, False negative, False positive, Heartworm, Heat treatment

\section{Background}

Diagnosis of heartworm infection in clinical practice relies upon detecting antigen of Dirofilaria immitis in serum, plasma, or whole blood samples from canine and feline patients. Historically, microfilaria tests were also widely used to test dogs; however, in most canine surveys antigen assays detect more infections than tests for microfilariae (Table 1). The greater sensitivity of antigen tests; the presence of naturally occurring, amicrofilaremic, or occult, infections; and the microfilaricidal effects of macrocyclic lactone-based heartworm preventives led to the perception that screening

\footnotetext{
* Correspondence: susan.little@okstate.edu

Department of Veterinary Pathobiology, Center for Veterinary Health

Sciences, Oklahoma State University, Stillwater, OK, USA
}

for microfilariae had limited clinical value [1, 2]. From 1992-2012, American Heartworm Society guidelines stated that less than $1 \%$ of microfilaremic dogs test antigennegative $[3,4]$, a perception apparently based on data from the 1980s when antigen tests were usually performed on pre-treated samples [5-7]. Due in part to recent data on blocked antigen causing false negative antigen test results, both the American Heartworm Society and the Companion Animal Parasite Council currently recommend testing all dogs using both a microfilaria test and an antigen test $[8,9]$.

The antigen targeted by the various commercial assays is primarily secreted by adult female heartworms; although all stages of $D$. immitis produce some antigen, the amount of circulating antigen present is considered largely 
Table 1 Canine surveys comparing prevalence of Dirofilaria immitis (Di) infection by detection of antigen (Ag) using commercial assays without pre-treatment of samples and detection of microfilaria (MF) by microscopy or PCR

\begin{tabular}{|c|c|c|c|c|c|}
\hline Country & $\mathrm{Di} \mathrm{Ag}+(\%)$ & Di MF by microscopy (\%) & Di MF by PCR (\%) & Other MF detected (\%) & Reference \\
\hline Italy & $65 / 630(10.3)$ & $79 / 630(12.5)$ & NR & $12 / 630(0.8)^{\mathrm{a}} ; 76 / 630(9.2)^{\mathrm{b}}$ & [13] \\
\hline Portugal & 65/696 (9.4) & $84 / 696(12.1)$ & 40/41 (97.6) & $3 / 696(0.4)^{b}$ & [14] \\
\hline Portugal & 78/304 (25.7) & $61 / 304(20.1)$ & NR & NR & {$[15]$} \\
\hline Romania & $16 / 194(8.2)$ & $11 / 194(5.7)$ & $11 / 24(45.8)$ & $12 / 194(6.2)^{c}$ & [16] \\
\hline Australia & 48/404 (11.9) & $23 / 404(5.7)$ & NR & $15 / 404(3.7)^{\mathrm{a}}$ & [24] \\
\hline Brazil & $8 / 611(1.3)$ & 6/611 (1.0) & NR & $42 / 611(6.9)^{\mathrm{a}}$ & {$[25]$} \\
\hline USA & $45 / 616(7.3)$ & $26 / 616(4.2)$ & NR & $6 / 616(1.0)^{\mathrm{a}}$ & [31] \\
\hline Costa Rica & 16/146 (11.0) & 17/146 (11.6) & $17 / 33(51.5)$ & $16 / 146(11.0)^{\mathrm{a}}$ & {$[48]$} \\
\hline Greece & $28 / 750(3.7)$ & $19 / 750(2.5)$ & NR & $10 / 750(1.3)^{a} ; 17 / 750(2.3)^{c}$ & [54] \\
\hline USA & $31-34 / 110(28.2-30.9)$ & $18 / 110(16.4)$ & NR & $1 / 110(0.9)^{\mathrm{a}}$ & {$[55]$} \\
\hline USA (Tennessee) & 93/673 (13.8) & 213/3608 (5.9) & NR & NR & {$[56]$} \\
\hline South Korea & $36 / 127(28.3)$ & $13 / 127(10.2)$ & NR & NR & {$[57]$} \\
\hline Dominican Republic & 18/104 (17.3) & 14/104 (13.5) & NR & NR & [58] \\
\hline Haiti & $55 / 210(26.2)$ & NR & $46 / 207(22.2)$ & $3 / 207(1.4)^{a}$ & [59] \\
\hline
\end{tabular}

${ }^{\mathrm{a}}$ Microfilaria of Acanthocheilonema reconditum detected

${ }^{\mathrm{b}}$ Microfilaria of Acanthocheilonema dracunculoides detected

'Microfilaria of Dirofilaria repens detected

Abbreviation: NR, not reported.

related to the number and age of the female heartworms present in the animal $[1,5]$. Although false positive results have been reported (see discussion below), commercial antigen tests are considered to be very specific, with most assays described with a specificity at or approaching $100 \%$. In contrast, the sensitivity of the different tests can vary widely in dogs and cats (Table 2, 3). This variance is usually attributed to the platform for a given antigen test, test performance characteristics, and the age and number of female heartworms present in the patients from which samples were collected $[2,10,11]$. The microtiter plate enzyme-linked immunosorbent assay (ELISA) is considered the most sensitive platform and detects antigen in as many as $\mathbf{8 5 . 7 \%}$ of dogs infected with a single adult female worm; reported sensitivity for microtiter plate ELISA when at least 3 adult female worms are present is 100\% [1]. Many of the lateral flow immunochromatographic assays and the membrane-bound ELISAs, which are designed to provide rapid in-clinic results, also demonstrate good sensitivity and can detect antigen in $46-76.2 \%$ of patients infected with a single female worm and $84-100 \%$ of patients with 3 or more female worms $[1,2,10]$. Repeated evaluation of the same test(s) can yield different performance characteristics due to differences in specimens included in the analysis, test kit version, procedures used, and method of heartworm infection verification [12].

\section{Discordant results}

Because of the increased sensitivity of antigen tests over microscopic detection of microfilariae alone, most surveys of naturally infected dogs that include both approaches document that antigen detection identifies more heartworm infections (Table 1). However, in some populations, a surprising number of samples are antigen-negative but microfilaria-positive. In comparing reported results from dogs with evidence of heartworm infection, $6.0-38.7 \%$ of dogs with $D$. immitis microfilariae were antigen-negative when tested [13-16]. This particular discordant result can be difficult to understand intuitively. If adult heartworms are present in a dog, mating, and producing a high enough level of microfilaremia to be recognized by microscopy, then adequate antigen should be available for detection. However, in most surveys, some dogs have microfilariae of $D$. immitis but remain antigen-negative even when the most sensitive antigen detection assays are used (Table 4).

Potential explanations for failing to detect antigen in dogs with circulating microfilariae include misidentification of microfilariae, death of adult worms with persistence of microfilariae, and transfusion of microfilaremic blood or transplacental transmission from a microfilaremic dam to her pups $[17,18]$. Microfilariae other than D. immitis commonly found in canine blood include Acanthocheilonema reconditum, A. dracunculoides and D. repens [19]. Laboratory confirmation of microfilaria as D. immitis and careful review of the history can explain some of the discordant results between microfilaria testing and antigen testing, and inherent limitations of test sensitivity may explain the remaining discrepancies. An antigen test which is $85-90 \%$ sensitive would be expected to miss approximately $10-15 \%$ of infections in 
Table 2 Reported performance characteristics of selected commercial heartworm antigen tests used in dogs

\begin{tabular}{|c|c|c|c|c|}
\hline Test & $\begin{array}{l}\text { \% Sensitivity (number of live adult female } \\
\text { heartworms) }\end{array}$ & \% Specificity & $\begin{array}{l}\text { Heartworm positive/total } \\
\text { tested }\end{array}$ & Reference \\
\hline$\overline{\text { DiroCHEK}^{\oplus}}$ & $85.7(1), 95(2), 100(\geq 3)$ & 100 & $108 / 208^{b, c, d, e}$ & [1] \\
\hline PetChek $^{\circledast}$ HTWM PF & $76.2(1), 85(2), 100(\geq 3)$ & 100 & & \\
\hline Solo Step ${ }^{\circledast}$ CHBatch & $71.4(1), 95(2), 96.5(\geq 3)$ & 100 & & \\
\hline Solo Step ${ }^{\circledast} \mathrm{CH}$ & $76.2(1), 95(2), 96.5(\geq 3)$ & 100 & & \\
\hline ICT Gold ${ }^{\oplus} \mathrm{HW}$ & $61.9(1), 85(2), 93(\geq 3)$ & 100 & & \\
\hline SNAP® Heartworm PF & $76.2(1), 85(2), 100(\geq 3)$ & 100 & & \\
\hline Witness ${ }^{\circledast} \mathrm{HW}$ & $71.4(1), 90(2), 94.7(\geq 3)$ & 100 & & \\
\hline AbboScreen $^{\mathrm{TM}}$ & $71.4(1), 100(2), 93(\geq 3)$ & 96 & & \\
\hline FILARIA IC (Italian) & $76.2(1), 85(2), 100(\geq 3)$ & 100 & & \\
\hline Witness $^{\mathrm{TM}} \mathrm{HW}$ (Australian) & $66.7(1), 90(2), 94.7(\geq 3)$ & 100 & & \\
\hline VetScan CHAT & 78 & 97 & $208 / 240^{\mathrm{b}, \mathrm{e}}$ & [2] \\
\hline SNAP® Heartworm RT & 84 & 97 & & \\
\hline Solo Step ${ }^{\circledast} \mathrm{CH}$ & 79 & 97 & & \\
\hline PetChek ${ }^{\circledR}$ HTWM PF & $45\left(0^{\mathrm{a}}\right), 77(1-2), 94(\geq 3)$ & 97 & $140 / 237^{e}$ & [10] \\
\hline DiroCHEK ${ }^{\circledR}$ & $40\left(0^{\mathrm{a}}\right), 71(1-2), 94(\geq 3)$ & 94 & & \\
\hline SNAP® Heartworm PF & $35\left(0^{\mathrm{a}}\right), 65(1-2), 94(\geq 3)$ & 98 & & \\
\hline Solo Step ${ }^{\circledast} \mathrm{CH}$ & $35\left(0^{\mathrm{a}}\right), 56(1-2), 90(\geq 3)$ & 98 & & \\
\hline AbboScreen & $30\left(0^{\mathrm{a}}\right), 46(1-2), 84(\geq 3)$ & 96 & & \\
\hline VetScan VS2 & 33 & 100 & $40 / 90^{e}$ & [11] \\
\hline SNAP® Heartworm RT & 90 & 100 & & \\
\hline SNAP® Heartworm RT & 90.9 & 98.8 & $84 / 150^{b, f}$ & [37] \\
\hline Witness ${ }^{\oplus}$ Heartworm & 97.0 & 96.4 & & \\
\hline Filarchek & 97.6 & 100 & $41 / 107$ & [60] \\
\hline VetScan & 92 & 100 & $25 / 49^{e}$ & [61] \\
\hline DiroCHEK ${ }^{\circledast}$ & $100(\geq 3)$ & 100 & NR & [62] \\
\hline Witness ${ }^{\circledast}$ Heartworm & 97.7 & 99.3 & $134 / 285^{e, f}$ & [63] \\
\hline
\end{tabular}

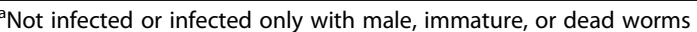

${ }^{\mathrm{b}}$ Heartworm infection established naturally

${ }^{c}$ Heartworm infection established by subcutaneous injection of third-stage larvae

${ }^{\mathrm{d}}$ Heartworm infection established by surgical transplantation

enfection verified by necropsy

Infection verified by comparison to DiroCHEK ${ }^{\oplus}$

Table 3 Reported performance characteristics of selected commercial heartworm antigen tests used in cats

\begin{tabular}{|c|c|c|c|c|}
\hline Test & $\%$ Sensitivity & $\%$ Specificity & Heartworm positive/total tested & Reference \\
\hline$\overline{\text { VetScan }}$ & 79.9 & 99.7 & $29 / 380^{a}$ & [61] \\
\hline DiroCHEK ${ }^{\circledast}$ & 89.7 & 100 & $39 / 81^{a, b}, c, d$ & [64] \\
\hline SNAP® Feline Triple ${ }^{\oplus}$ & 89.3 & 99.5 & $26 / 238^{a, e}$ & [65] \\
\hline DiroCHEK ${ }^{\circledast}$ & 78.9 & 98.1 & $19 / 330^{a, b}$ & [66] \\
\hline SNAP® Feline HTWM & 73.7 & 99.4 & & \\
\hline SNAP® Feline HTWM & 79.3 & 98.0 & $29 / 380^{a, b}$ & [67] \\
\hline CHAT Canine HTWM & 79.3 & 99.7 & & \\
\hline DiroCHEK ${ }^{\circledast}$ & 86.2 & 99.1 & & \\
\hline
\end{tabular}

\footnotetext{
Infection verified by necropsy
}

${ }^{\mathrm{b}}$ Heartworm infection established naturally

'Heartworm infection established by subcutaneous injection of third-stage larvae

${ }^{\mathrm{d}}$ Heartworm infection established by surgical transplantation

enfection verified by comparison to PetChek $^{\circledR}$ HTWM PF 
Table 4 Results from Dirofilaria immitis (Di) antigen (Ag) and microfilariae (MF) tests on dogs for naturally occurring heartworm infection. In each study listed, microfilariae were confirmed as Dirofilaria immitis by acid phosphatase stain or by PCR unless otherwise noted

\begin{tabular}{|c|c|c|c|c|c|}
\hline No. of dogs (\% positive) ${ }^{a}$ & $\begin{array}{l}D i A g+D i M F+ \\
(\%)\end{array}$ & $\begin{array}{l}D i A g+D i M F- \\
(\%)\end{array}$ & $\begin{array}{l}\text { Di Ag - Di MF + } \\
(\%)\end{array}$ & $\begin{array}{l}\text { Di Ag - Di MF - } \\
(\%)\end{array}$ & Reference \\
\hline $630(16.2)^{b}$ & $42(6.7)$ & $23(3.7)$ & $37(5.9)^{b}$ & $555(88.1)$ & {$[13]$} \\
\hline $696(15.1)$ & $49(7.0)$ & $16(2.3)$ & $41(5.9)$ & $591(84.9)$ & [14] \\
\hline $304(27.3)$ & $56(18.4)$ & $22(7.2)$ & $5(1.6)$ & $221(72.7)$ & {$[15]$} \\
\hline $24(62.5)$ & $6(25.0)$ & $4(16.7)$ & $5(20.8)$ & $9(37.5)$ & [16] \\
\hline $404(12.1)$ & $21(5.2)$ & $25(6.2)$ & $3(0.7)$ & $355(87.9)$ & {$[24]$} \\
\hline $616(7.6)$ & $24(3.9)^{c}$ & $21(3.4)$ & $2(0.3)^{b, c}$ & $569(92.4)$ & [31] \\
\hline $104(18.3)$ & $13(12.5)$ & $5(4.8)$ & $1(1.0)$ & $85(81.7)$ & [58] \\
\hline
\end{tabular}

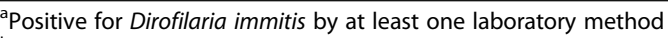

${ }^{b}$ Inferred from text description of reported results and prior to heat treatment of samples

${ }^{c}$ Microfilariae identified by morphology alone

practice; when confidence intervals are included, the range of potential missed infections is wider. Blocked antigen is a more recently re-identified potential cause of false negative antigen test results and one which can be addressed by pre-treating the sample prior to testing. By freeing antigen trapped in immune complexes, detection in some patients is improved. Heat pretreatment, with or without addition of EDTA, is a common method for disrupting immune complexes in many systems; dissociation of complexes may also be achieved using pepsin or an acidic $\mathrm{pH}$ [20-22].

\section{Unexpectedly negative antigen tests}

Although commercial antigen tests play a critical role in detecting $D$. immitis infections, some data suggest that relying on antigen tests alone and forgoing efforts at microfilaria detection can result in failing to identify heartworm infection in some patients. For example, using two different commercial assays, antigen was not detected in $21.6 \%$ or $24 \%$ of serum samples from dogs from Argentina with $D$. immitis-confirmed microfilaremia [23], and $38.7 \%$ of microfilaremic dogs in Portugal with PCR confirmed $D$. immitis microfilaremia did not have detectable antigen present [14]. Antigen tests also sometimes fail to detect infection in dogs with adult $D$. immitis confirmed at necropsy. In Australia, 8/15 (53.3\%) dogs with adult $D$. immitis recovered were antigen-negative, and 6/14 (42.9\%) confirmed heartworm infected dogs in Brazil were antigen-negative [24, 25].

A possible explanation for many of these antigennegative discordant results in dogs confirmed infected by either detection of microfilariae or recovery of adult heartworms at necropsy is the presence of blocked antigen $[5,26]$. In some patients infected with heartworm, antigen is present in circulation but apparently trapped in immune complexes, preventing detection on commercial assays; pre-treating serum or plasma samples to disrupt the immune complexes and then repeating the test changes these false negative antigen tests to true positive $[26,27]$. Pretreatment of samples to disrupt immune complexes was routinely practiced when antigen tests for D. immitis first became available [5-7]; diagnostic labs often pre-treat samples prior to running antigen assays for other pathogens including fungi (e.g. Histoplasma sp., Aspergillus sp.), viruses (HIV, dengue), protozoal agents (e.g. Leishmania sp.), and others [20-22].

\section{Heat reversal to support heartworm diagnosis}

Heat treatment of samples prior to running heartworm antigen tests has been demonstrated to result in increased detection of antigen in samples from both dogs and cats in a number of different studies in recent years. These reports include samples from both experimentally infected, necropsy-confirmed $D$. immitis infections and natural infections. Evaluation of samples collected from cats 196 days (6.5 months) and 224 days (7.5 months) after experimental infection with third-stage larvae and confirmed to harbor adult heartworms at necropsy demonstrated that 5/6 (83.3\%) changed from false negative to true positive after heat pretreatment; one cat was antigen-positive with heat pretreatment as early as day 168 (5.6 months) [28]. These data suggest cats may be particularly likely to have blocked antigen, especially early in infection when antibodies are at peak levels. Similarly, heat pretreatment of samples from dogs experimentally infected with third-stage larvae and confirmed to have adult heartworms at necropsy has been shown to improve and allow earlier detection of antigen. In one study, antigen was not detected in canine samples collected 128 days (4.3 months) after infection, but after heat pretreatment, all $(8 / 8)$ were positive. Evaluation of samples collected 150-152 days (5 months) after infection showed 6/14 (42.9\%) were positive before heat pretreatment but all (14/14) were positive after heat pretreatment [29]. Another study showed that heat pretreatment of samples allowed detection of antigen in 
experimentally infected dogs an average of one month earlier than when using unheated samples [30].

In surveys of dogs from animal shelters in the United States for naturally occurring heartworm infection, 11/154 (7.1\%) and 29/558 (5.2\%) canine samples changed from negative to positive on microtiter well based ELISA assays after pretreatment of samples by heating [27, 31]. Furthermore, when antigen-positive samples were subjected to pretreatment by heating, the optical density of $14 / 101$ (13.8\%) positive samples increased by $>50 \%$, indicating that immune complexes likely form in many heartworm-infected dogs, but the degree to which the heartworm antigen is blocked varies [27]. A survey of dogs in animal shelters in Romania revealed that after heat pretreatment, 52/194 (26.8\%) samples changed from negative to positive on antigen test [16]. Heat pretreatment also increases the number of antigen-positive cat samples. Evaluation of samples from shelter cats from the southern United States revealed 21/385 (5.5\%) became positive after heat pretreatment; antibody to $D$. immitis was significantly more common in samples from cats that became antigen-positive after heat pretreatment than in samples that remained antigen-negative, supporting the interpretation that heat pretreatment was revealing true positives [32].

Reversal from antigen-negative to positive after pretreatment by heating also occurs in some pet dogs infected with heartworm. In one study, samples from 15 heartworminfected pet dogs managed with either monthly ivermectin or monthly moxidectin preventive and an initial 30 day course of doxycycline, and that tested negative on an antigen test within 24 months of starting treatment, were reevaluated to determine if this therapy had resulted in the development of false negative antigen tests. Indeed, "negative" samples from $8 / 15$ (53.3\%) dogs changed to positive after pretreatment [33]. In Brazil, samples from 22 pet dogs naturally infected with heartworms and managed with topical moxidectin/imidacloprid and doxycycline were evaluated.
After 6 months of this therapy, samples from 6/14 (42.9\%) dogs changed from negative to positive on the antigen test after heat pretreatment of the samples, and after 12 months, $1 / 21$ (4.8\%) changed to positive [34]. Interestingly, when the effect of moxidectin/imidacloprid treatment on adult $D$. immitis was evaluated in dogs experimentally infected via surgical transplantation of adult worms, pretreatment of serum with heating did not appear to provide additional sensitivity [35], a finding that may reflect the different host immune response invoked by transplantation of adult worms compared to natural or experimental infection by third-stage larvae. Heat pretreatment also proved helpful in confirming heartworm infection in a pet dog in Portugal co-infected with both $D$. immitis and $D$. repens [36] and was recently reported as helpful in resolving discordant results in a comparative evaluation of commercially available antigen tests [37].

Identified risk factors that appear to indicate samples from dogs in animal shelters are likely to change from negative to positive with heat pretreatment included concomitant presence of microfilariae and recent administration of a heartworm preventive [31]. In contrast, initial work shows that samples from pet dogs free of infection and maintained on heartworm preventives appear unlikely to become positive with heat pretreatment. Evaluation of samples from 201 pet dogs in Oklahoma (USA) for D. immitis antigen both before and after heat treatment revealed only one $(0.5 \%)$ changed from negative to positive [38]. Although further research is needed, together these studies allow general recommendations to be made on which patients would benefit the most from heat pretreatment prior to antigen testing (Table 5).

\section{Summary of data from diagnostic records}

To explore this issue using clinical samples, we summarized the diagnostic records from 162 canine patients from the

Table 5 Patients ${ }^{a}$ most likely to benefit from heat pretreatment of samples prior to antigen testing for Dirofilaria immitis

\begin{tabular}{|c|c|}
\hline Patient type & Reason \\
\hline $\begin{array}{l}\text { Dogs in endemic areas not on preventive, especially } \\
\text { young dogs }\end{array}$ & $\begin{array}{l}\text { Allows detection of infection earlier than testing non-pretreated } \\
\text { samples. }\end{array}$ \\
\hline Dogs with an inconsistent history of preventive use & $\begin{array}{l}\text { Macrocyclic lactones given intermittently may begin to kill adult } \\
\text { worms, leading to inflammation and immune complex formation. } \\
\text { Microfilariae are also less likely to be detected in patients that have } \\
\text { received preventives. }\end{array}$ \\
\hline
\end{tabular}

Heartworm-infected dogs recently treated with adulticide or managed only with preventive and doxycycline
Inflammation induced by dead and dying worms may lead to immune complex formation that masks antigen, preventing detection in unheated samples. Residual antigen may be detected both with and without heat pretreatment of samples in dogs recently treated for heartworm infection.

If microfilariae are D. immitis, then heat pretreatment is likely to change the result to true positive.

antigen-negative

Cats in endemic areas not on preventive
Blocked antigen is very common in infected cats, particularly early in infection when immune response is most pronounced.

${ }^{a}$ Exercise caution in interpreting heartworm antigen test results, with or without heat pretreatment, on samples from dogs living in areas where infection with Angiostrongylus vasorum or Spirocerca lupi is common; both have been shown to cause false positive results on some antigen tests (see Table 8 ) 
USA, including samples from Arkansas, California, Florida, Hawaii, Illinois, Oklahoma, Tennessee, Texas and Virginia. Each sample included in this review was tested for antigen before and after heat treatment and for microfilariae of $D$. immitis by modified Knott as previously described [26, 39]; additional samples tested from 12 other states but which did not have all three assays performed were excluded. All testing was performed at the Oklahoma Animal Disease Diagnostic Laboratory in 2017. For antigen testing, $1 \mathrm{ml}$ of whole blood was centrifuged at $1500 \times g$ for $10 \mathrm{~min}$, plasma removed and either tested directly (antigen test before heat) or heated to $104{ }^{\circ} \mathrm{C}$ for $10 \mathrm{~min}$, the resultant coagulum centrifuged at $16,000 \times g$ for $10 \mathrm{~min}$, and the supernatant tested (antigen test after heat) [26]. All antigen testing used a commercial assay according to manufacturer's instructions (DiroCHEK ${ }^{\circ}$ Z Zoetis, Kalamazoo, Michigan, USA). For modified Knott test, $9 \mathrm{ml}$ of $2 \%$ formalin was added to $1 \mathrm{ml}$ of whole blood, the sample mixed by inversion, and then centrifuged at $1500 \times g$ for $10 \mathrm{~min}$. The supernatant was decanted, the pellet stained with $2 \%$ methylene blue, and transferred to a glass microscope slide for examination [39]. Any microfilariae present were counted and the length and width of up to 10 individual microfilariae recorded.

Prior to heat treatment, $13.0 \%(21 / 162)$ of dogs were positive for $D$. immitis, including 14 by only antigen, six by only microfilaria detection, and one positive for both. After heat treatment, $24.7 \%$ (40/162) of dogs were positive for $D$. immitis, including 33 by only antigen. All six dogs that were microfilaria-positive for $D$. immitis but antigen-negative prior to heat treatment became antigen-positive following heat treatment (Table 6). All of these dogs were from Oklahoma and Texas, a finding that reflects the geographical distribution of most samples tested in this state diagnostic laboratory. Of the 17 dogs that changed from antigen-negative to antigenpositive after heat treatment but that did not have microfilariae detected, 16 were from Oklahoma and Texas and one was from Florida.

This sample set does not represent a cross-section of all dogs tested for heartworm. Samples are more likely to be submitted to our diagnostic laboratory for testing when microfilariae are seen in a dog that tests antigen negative in clinic or when the veterinarian doubts the results of an antigen test based on history or physical examination. Nonetheless, the finding that the false negative antigen tests in microfilaremic dogs submitted to this laboratory reliably change to true positive with heat pretreatment is of interest. We do not know the true heartworm infection status of the 17 amicrofilaremic dogs whose samples changed to positive with heat pretreatment but suspect some of these may represent early, prepatent infections. Heat pretreatment can allow earlier detection of heartworm infection in both dogs and cats [28-30].

\section{Identification of microfilariae}

Microfilariae of several species may be found in canine blood although the prevalence of each varies geographically. Commonly reported organisms include Dirofilaria immitis, $D$. repens, $A$. reconditum and $A$. dracunculoides [39-41]. All four organisms infect dogs in parts of Europe, Asia and Africa, but in the Americas, autochthonous canine infections of only $D$. immitis and $A$. reconditum have been reported $[39,41]$. Diagnostic laboratories often identify microfilariae recovered on Knott test based on differences in morphology and size. For example, $D$. immitis is described as having a tapered head and straight body and tail, whereas $A$. reconditum bears a blunt head, curved body, and variably-shaped tail which may be either hooked or curved [39, 42]. Because multiple examples of ideal microfilaria are not present in every clinical sample, size measurements are also used as a primary criteria to identify the species present. Unfortunately, the length and width of each species varies widely among commonly used textbooks and other references (Table 7) and is also influenced by the fixation techniques used [43]. This variation can lead to misidentification of microfilariae, particularly when multiple Dirofilaria spp. or Acanthocheilonema spp. are present in a given area. In Romania, where co-infection with $D$. immitis and $D$. repens are common, identifying microfilariae by morphometric description alone can produce uncertain results $[16,43,44]$.

Other approaches to microfilaria identification include histochemical stain using either acid phosphatase or Giemsa, and molecular approaches such as PCR with or

Table 6 Results of testing canine ${ }^{a}$ blood samples for antigen (Ag) of Dirofilaria immitis (Di) before and after heat pretreatment of samples and for microfilariae (MF) of D. immitis by modified Knott followed by morphological identification

\begin{tabular}{llllll}
\hline Antigen test performed & $\begin{array}{l}\text { Number } \\
(\% \text { positive) }\end{array}$ & $\begin{array}{l}\text { Di Ag + Di MF } \\
(\%)\end{array}$ & $\begin{array}{l}\text { Di Ag + Di MF - } \\
(\%)\end{array}$ & $\begin{array}{l}\text { Di Ag - Di MF + } \\
(\%)\end{array}$ & $\begin{array}{l}\text { Di Ag - Di MF - } \\
(\%)\end{array}$ \\
\hline Before heat & $21 / 162(13.0)$ & $1(0.6)$ & $14(8.6)$ & $6(3.7)^{c}$ & $141(87.0)^{c}$ \\
After heat & $40 / 162(24.7)$ & $7(4.3)^{c}$ & $33(20.4)^{c}$ & $0(0)$ & $122(75.3)^{c}$ \\
\hline
\end{tabular}

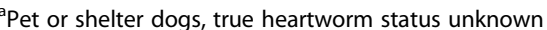

${ }^{\mathrm{b}}$ Positive for Dirofilaria immitis by at least one laboratory method

'Three samples had microfilariae of Acanthocheilonema reconditum. The first contained both $D$. immitis and A. reconditum microfilariae and was negative before but positive after heat treatment. The second had only $A$. reconditum microfilariae and was negative before and negative after heat treatment. The third had only microfilariae of $A$. reconditum and was negative before and positive after heat treatment 
Table 7 Reported length and width measurements of microfilaria of Dirofilaria immitis, D. repens ${ }^{\mathrm{a}}$, Acanthocheilonema reconditum, and $A$. dracunculoides ${ }^{\mathrm{a}}$ recovered by modified Knott (formalin fixed)

\begin{tabular}{|c|c|c|c|c|c|}
\hline $\begin{array}{l}\text { Measurement } \\
(\mu \mathrm{m})\end{array}$ & Dirofilaria immitis & Dirofilaria repens ${ }^{a}$ & $\begin{array}{l}\text { Acanthocheilonema } \\
\text { reconditum }\end{array}$ & $\begin{array}{l}\text { Acanthocheilonema } \\
\text { dracunculoides }^{\mathrm{a}}\end{array}$ & Reference \\
\hline \multirow[t]{7}{*}{ Length } & $295-325$ & $268-360$ & $250-288$ & $189-230$ & [39] \\
\hline & 290-330 & $300-360$ & $260-283$ & $190-247$ & [42] \\
\hline & 295-308 & 359-380 & $259-270$ & $253-266$ & [43] \\
\hline & $307-332$ & 360 & $246-292$ & $\sim 300$ & {$[45]$} \\
\hline & $231-288^{b}$ & $302-344^{b}$ & $N R$ & NR & {$[46]$} \\
\hline & $\geq 315$ & NR & $<290$ & $<290$ & [68] \\
\hline & $280-320$ & NR & $215-270$ & NR & {$[69]$} \\
\hline \multirow[t]{6}{*}{ Width } & $5.0-7.5$ & $5.0-8.0$ & $4.5-5.5$ & $5.0-6.0$ & [39] \\
\hline & $5.0-7.0$ & $6.0-8.0$ & 4.0 & $4.0-6.5$ & [42] \\
\hline & $6.0-6.6$ & $8.3-9.5$ & $4.1-5.1$ & $4.6-5.6$ & [43] \\
\hline & 6.8 & 12.0 & $4.7-5.8$ & $N R$ & [45] \\
\hline & $6.1-7.2$ & NR & $4.7-5.8$ & $N R$ & {$[69]$} \\
\hline & $6.0-7.0$ & NR & $<5.6$ & NR & {$[70]$} \\
\hline
\end{tabular}

${ }^{a}$ Autochthonous infections not documented to occur in North America

${ }^{\mathrm{b}}$ Microfilaria recovered by thick smear (methanol fixed)

without sequence confirmation. With acid phosphatase, microfilaria of $D$. immitis stains red at distinct focal points near the anal and excretory pore, $D$. repens stains only at the anal pore, A. dracunculoides stains at the anal pore, the excretory pore, and the internal body, while $A$. reconditum stains diffusely pink throughout [40, 45]. Using Giemsa stain, D. immitis is characterized by a longer cephalic space and the absence of distinct anterior nuclei when compared to $D$. repens [46]. Molecular identification has also commonly been used to confirm identity of microfilaria in blood with targets such as cox1, $12 S \mathrm{rDNA}$, and $16 \mathrm{~S} \mathrm{rDNA}$ often employed [47, 48]. Unlike antigen testing, PCR can only detect patent infections when microfilariae are present in circulation; the main advantage of PCR over microscopic procedures such as the Knott test is that it allows confirmation of species by specific primers or sequencing.

\section{Additional explanations for false negative and false positive heartworm tests}

False negative results, in which a dog or cat infected with heartworm does not have detectable antigen, can occur for a number of reasons other than antigen blocking. Until recently it was thought that antigen was not detectable until six months after infection, and that in dogs given heartworm preventives, antigen detection may be delayed as long as nine months after infection $[1,8]$. More recent studies have documented that with heat pretreatment, antigen can be detected as early as 4.2 months in dogs or 5.6 months in cats [28-30]. In addition, recent work has shown that administration of preventives and doxycycline to an infected dog does interfere with antigen detection, but this false negative can be reversed with heat pretreatment of samples [33]. However, if dogs or cats harbor infections that have been established less than four or five months, respectively, immature $D$. immitis may be present and the antigen test negative regardless of how it is performed.

Testing platforms also differ in sensitivity. Infection with only one or two adult female heartworms may result in a negative patient-side assay but positive microtiter well result due to the greater sensitivity of the latter approach (Table 2, 3). Heat pretreatment has been shown to improve sensitivity of both patient-side and microtiter plate assays, and re-evaluation of test performance using pretreatment of samples was recently shown to resolve most discordant results [26, 37]. Finally, if only male worms are present, antigen is unlikely to be detected $[4,8]$. The effect of heat pretreatment, if any, on detection of antigen in male-only infections has not been reported and such infections are considered uncommon and clinically unimportant.

The American Heartworm Society guidelines state that the current generation of heartworm antigen tests are "nearly $100 \%$ specific" and the label information on the assays and data from available comparative studies support this assertion (Table 2, 3) [8]. However, false positive results have been reported in samples from dogs and some wildlife species infected with nematodes other than D. immitis (Table 8). Importantly, false positives have been reported without any heat pretreatment of the samples [49-53]. Known causes of false positive heartworm antigen tests include infection with Spirocerca lupi, Angiostrongylus vasorum and A. odendhali, while 
Table 8 Nematodes known or suspected to induce false positive results in canine serum, plasma, or whole blood samples tested on heartworm antigen tests without heat pretreatment of samples

\begin{tabular}{|c|c|c|c|}
\hline Species of nematode & $\begin{array}{l}\text { Dirofilaria immitis antigen } \\
\text { detected (number positive/ } \\
\text { number tested) }\end{array}$ & Origin of samples tested & Reference \\
\hline Angiostrongylus vasorum & $0 / 16$ to $8 / 16^{a}$ & $\begin{array}{l}\text { Domestic dogs experimentally infected with } A n . \\
\text { vasorum }\end{array}$ & [49] \\
\hline \multirow[t]{2}{*}{ Spirocerca lupi } & $2 / 19$ to $14 / 48^{a}$ & $\begin{array}{l}\text { Domestic dogs } s^{c} \text { with confirmed esophageal spirocercosis, } \\
\text { resided in area without autochthonous } D \text {. immitis }\end{array}$ & \multirow[t]{2}{*}[50]{} \\
\hline & $8 / 32$ & $\begin{array}{l}\text { Domestic dogs }{ }^{c} \text { with confirmed esophageal spirocercosis; } \\
\text { PCR negative for D. immitis microfilaria }\end{array}$ & \\
\hline Acanthocheilonema odendhali & $15 / 15$ & $\begin{array}{l}\text { California sea lions (Zalophus californianus) with microfilaria } \\
\text { of } A \text {. odendhali }\end{array}$ & [51] \\
\hline Dirofilaria ursi & $6 / 10$ & $\begin{array}{l}\text { North American brown bear (Ursus arctos) presumed infected } \\
\text { based on geographic location (northern Canada) }\end{array}$ & [52] \\
\hline Angiostrongylus vasorum & $1 / 3$ to $3 / 3^{a}$ & $\begin{array}{l}\text { Domestic dogs }{ }^{c} \text { naturally infected with An. vasorum confirmed } \\
\text { by serum antigen test for An. vasorum and fecal; history of } \\
\text { consistent heartworm preventive use }\end{array}$ & [53] \\
\hline Dirofilaria repens & $0 / 4$ to $2 / 4^{a, b}$ & $\begin{array}{l}\text { Domestic dogs }{ }^{\complement} \text { naturally infected with } D \text {. repens as confirmed } \\
\text { by microfilaria and subcutaneous nodules }\end{array}$ & [53] \\
\hline
\end{tabular}

${ }^{a}$ Results varied depending on heartworm antigen assay used

bWith heat pretreatment of samples, increased to $4 / 4$

'Pet dogs, true heartworm status unknown

related nematodes, such as other Dirofilaria spp., Dracunculus insignis and Onchocerca spp., are also thought to induce false positive results [49-53].

In one recent publication, heat pretreatment was reported to reveal more false positives than was found using non-pretreated samples. Samples from three dogs with $A n$. vasorum and four dogs with $D$. repens were tested with six different heartworm tests. Although positive antigen test results were evident prior to heat treatment, additional positives were detected after heat treatment [53]. Cross-reactions on D. immitis antigen tests have been previously documented in dogs infected with $A n$. vasorum [49] but not D. repens. Co-infections with $D$. immitis and $D$. repens are commonly reported in areas where both occur [13, 16, 36, 54]; because all four dogs with $D$. repens in the cross-reaction paper were client-owned, necropsy results to support the absence of D. immitis were not available [53]. The effect of heat pretreatment on revealing additional false positives is not yet fully understood, but caution should be taken in interpreting results from samples pretreated prior to $D$. immitis antigen testing, particularly in populations likely to harbor infections with An. vasorum or S. lupi, nematodes known to cross-react on heartworm antigen tests.

\section{Conclusions}

Heartworm antigen tests provide a convenient, sensitive, and specific means of identifying $D$. immitis infection in veterinary patients. However, recent research from multiple laboratories shows that false negative results may be present in many individual patients. For this reason, heat pretreatment of serum or plasma samples offers a valuable adjunct to traditional heartworm testing. As demonstrated in the present paper, this approach also allows resolution of $D$. immitis microfilaria-positive but antigen-negative results; in addition, heat pretreatment has been shown to resolve discordant results between different heartworm assays [37]. Although commonly described as virtually $100 \%$ specific, false positive results also have been reported and thus care should be taken in interpreting heartworm tests from dogs where autochthonous infections with An. vasorum or S. lupi occur regardless of whether heat pretreatment is performed.

\section{Abbreviations \\ 12S rDNA: 125 ribosomal RNA gene; 165 rDNA: 165 ribosomal RNA gene; Ag: Antigen; cox1: Cytochrome c oxidase subunit 1; ELISA: Enzyme-linked immunosorbent assay; MF: Microfilaria; PCR: Polymerase chain reaction.}

\section{Acknowledgements}

We are grateful to the many veterinarians, researchers, and industry scientists working to better understand and improve heartworm diagnostic testing. Publication of this paper has been sponsored by Bayer Animal Health in the framework of the 13th CVBD World Forum Symposium.

Ethical approval and consent to participate Not applicable.

Funding

Funding to support this review was provided by the Krull-Ewing Endowment at Oklahoma State University.

\section{Availability of data and materials}

The summary datasets used and/or analyzed during the present study are available from the corresponding author upon reasonable request. 


\section{Authors' contributions}

SL and MS conceived of and developed the review and prepared the draft manuscript. MW and YN performed the heartworm diagnostic tests, collated the data, and interpreted the results. All authors read and approved the final manuscript.

\section{Consent for publication}

Not applicable.

\section{Competing interests}

$S L$ and $Y N$ have received honoraria or research grants from companies that manufacture heartworm diagnostic tests, preventives, and treatments. The other authors have no competing interests.

\section{Publisher's Note}

Springer Nature remains neutral with regard to jurisdictional claims in published maps and institutional affiliations.

\section{Received: 18 November 2017 Accepted: 21 February 2018}

Published online: 20 March 2018

\section{References}

1. McCall JW, Suprakorndej BS, Donoghue AR, Turnbull RK. Evaluation of the performance of canine heartworm antigen test kits licensed for use by veterinarians and canine heartworm antigen tests conducted by diagnostic laboratories. In: Seward LE, Knight DH, editors. Recent Advances in Heartworm Disease Symposium '01. Batavia, Illinois: American Heartworm Society; 2001. p. 135-40.

2. Atkins CE. Comparison of results of three commercial heartworm antigen test kits in dogs with low heartworm burdens. J Am Vet Med Assoc. 2003; 222:1221-3.

3. American Heartworm Society. Recommended procedures for the diagnosis and management of heartworm (Dirofilaria immitis) infection. In: Soll MD, editor. Proceedings of the Heartworm Symposium '92. Austin: American Heartworm Society; 1992. p. 289-94.

4. American Heartworm Society. Current guidelines for the diagnosis, prevention, and management of heartworm (Dirofilaria immitis) infection in cats (revised January 2012) 2012. https://heartwormsociety.org/images/pdf/ 2012-AHS-Feline-Guidelines.pdf. Accessed 1 Feb 2012.

5. Weil GJ, Malane MS, Powers KG, Blair LS. Monoclonal antibodies to parasite antigens found in the serum of Dirofilaria immitis-infected dogs. J Immunol. 1985;134:1185-91.

6. Brunner CJ, Hendrix CM, Blagburn BL, Hanrahan LA. Comparison of serologic tests for detection of antigen in canine heartworm infections. J Am Vet Med Assoc. 1988;192:1423-7.

7. Tonelli QJ, Quentin AB. Factors affecting the accuracy of enzyme immunoassays for Dirofilaria immitis adult antigen. In: Otto GF, editor. Proceedings of the Heartworm Symposium '89. Washington, DC: American Heartworm Society; 1989. p. 161-5.

8. American Heartworm Society. Current canine guidelines for the prevention, diagnosis, and management of heartworm (Dirofilaria immitis) infection in dogs (revised July 2014). 2014. https://heartwormsociety.org/images/pdf/ 2014-AHS-Canine-Guidelines.pdf. Accessed 1 Sept 2017

9. Companion Animal Parasite Council: CAPC Heartworm Guidelines. 2017. https://capcvet.org/guidelines/heartworm/. Accessed 1 Sept 2017.

10. Courtney $\mathrm{CH}$, Zeng Q-Y. Comparison of heartworm antigen test kit performance in dogs having low heartworm burdens. Vet Parasitol. 2001;96: 317-22.

11. Lee AC, Bowman DD, Lucio-Forster A, Beall MJ, Liotta JL, Dillon R. Evaluation of a new in-clinic method for the detection of canine heartworm antigen. Vet Parasitol. 2011;177:387-91.

12. Courtney $\mathrm{CH}$. Comparing the performance of heartworm antigen tests in dogs. In: Soll MD, editor. Recent Advances in Heartworm Disease Symposium '01. Batavia, Illinois: American Heartworm Society; 2001. p. 105-10.

13. Magi M, Guardone L, Prati MC, Tozzini G, Torracca B, Monni G, et al. Canine filarial infections in Tuscany, central Italy. J Helminthol. 2012:86:113-6.

14. Alho AM, Landum M, Ferreira C, Meireles J, Gonçalves L, de Carvalho LM, et al. Prevalence and seasonal variations of canine dirofilariosis in Portugal. Vet Parasitol. 2014;206:99-105.
15. Vieira AL, Vieira MJ, Oliveira JM, Simões AR, Diez-Baños P, Gestal J. Prevalence of canine heartworm (Dirofilaria immitis) disease in dogs of central Portugal. Parasitology. 2014;21:5.

16. Ciucă L, Genchi M, Kramer L, Mangia C, Miron LD, Prete LD, et al. Heat treatment of serum samples from stray dogs naturally exposed to Dirofilaria immitis and Dirofilaria repens in Romania. Vet Parasitol. 2016:225:81-5.

17. Underwood PC, Harwood PD. Survival and location of the microfilariae of Dirofilaria immitis in the dog. J Parasitol. 1939;25:23-33.

18. Todd KS Jr, Howland TP. Transplacental transmission of Dirofilaria immitis microfilariae in the dog. J Parasitol. 1983;69:371.

19. Ortega-Mora LM, Gomez-Bautista M, Rojo-Vazquez FA. The acid phosphatase activity and morphological characteristics of Dipetalonema dracunculoides (Cobbold, 1870) microfilariae. Vet Parasitol. 1989:33:187-90.

20. Wheat $L$, Walsh TJ. Diagnosis of invasive aspergillosis by galactomannan antigenemia detection using an enzyme immunoassay. Eur J Clin Microbiol Infect Dis. 2008;27:245-51.

21. Swartzentruber S, LeMonte A, Witt J, Fuller D, Davis T, Hage C, et al. Improved detection of Histoplasma antigenemia following dissociation of immune complexes. Clin Vacc Immunol. 2009;16:320-2.

22. Beall MJ, Arguello-Marin A, Drexel J, Liu J, Chandrashekar R, Alleman AR. Validation of immune complex dissociation methods for use with heartworm antigen tests. Parasit Vectors. 2017;10:481.

23. Vezzani D, Fontanarrosa MF, Eiras DF. Are antigen test kits efficient for detecting heartworm-infected dogs at the southern distribution limit of the parasite in South America? Preliminary results. Res Vet Sci. 2008:85:113-5.

24. Bidgood A, Collins GH. The prevalence of Dirofilaria immitis in dogs in Sydney. Aust Vet J. 1996;73:103-4

25. Alves LC, de Almeida Silva LV, Faustino MA, McCall JW, Supakonderj P, Labarthe NW, et al. Survey of canine heartworm in the city of Recife, Pernambuco, Brazil. Mem Inst Oswaldo Cruz. 1999:94:587-90.

26. Little SE, Munzing C, Heise SR, Allen KE, Starkey LA, Johnson EM, et al. Pretreatment with heat facilitates detection of antigen of Dirofilaria immitis in canine samples. Vet Parasitol. 2014;203:250-2.

27. Velasquez L, Blagburn BL, Duncan-Decoq R, Johnson EM, Allen KE, Meinkoth $J$, et al. Increased prevalence of Dirofilaria immitis antigen in canine samples after heat treatment. Vet Parasitol. 2014:206:67-70.

28. Little SE, Raymond MR, Thomas JE, Gruntmeir J, Hostetler JA, Meinkoth JH, et al. Heat treatment prior to testing allows detection of antigen of Dirofilaria immitis in feline serum. Parasit Vectors. 2014;7:1.

29. Lee ACY, Rude KM, Drake J, Hostetler JA, Bowman DD. Detection of Dirofilaria immitis antigen 128 days post-infection in heat-treated canine serum. In: Proceedings, 59th Annual AAVP Meeting. Boston: MA; 2015.

30. Carmichael J, McCall S, DiCosty U, Mansour A, Roycroft L. Evaluation of Dirofilaria immitis antigen detection comparing heated and unheated serum in dogs with experimental heartworm infections. Parasit Vectors. 2017;10:486.

31. DiGangi BA, Dworkin C, Stull JW, O'Quin J, Elser M, Marsh AE, et al. Impact of heat treatment on Dirofilaria immitis antigen detection in shelter dogs. Parasit Vectors. 2017:10:483.

32. Gruntmeir JM, Adolph CB, Thomas JE, Reichard MV, Blagburn BL, Little SE. Increased detection of Dirofilaria immitis antigen in cats after heat pretreatment of samples. J Fel Med Surg. 2017;19:1013-6.

33. Drake J, Gruntmeir J, Merritt $H$, Allen L, Little SE. False negative antigen tests in dogs infected with heartworm and placed on macrocyclic lactone preventives. Parasit Vectors. 2015:8:68

34. Bendas AJR, Mendes-de-Almeida F, Von Simson C, Labarthe N. Heat pretreatment of canine samples to evaluate efficacy of imidacloprid + moxidectin and doxycycline in heartworm treatment. Parasit Vectors. 2017;10:246.

35. Savadelis MD, Ohmes CM, Hostetler JA, Settje TL, Zolynas R, Dzimianski MT, et al. Assessment of parasitological findings in heartworm-infected beagles treated with Advantage Multi ${ }^{\circledast}$ for dogs (10\% imidacloprid $+2.5 \%$ moxidectin) and doxycycline. Parasit Vectors. 2017;10:245.

36. Maia C, Lorentz S, Cardoso L, Otranto D, Naucke TJ. Detection of Dirofilaria repens microfilariae in a dog from Portugal. Parasitol Res. 2016:115:441-3.

37. Starkey LA, Bowles JV, Payton ME, Blagburn BL. Comparative evaluation of commercially available point-of-care heartworm antigen tests using wellcharacterized canine plasma samples. Parasit Vectors. 2017;10:475

38. Nafe L, Little SE, DeMars P, Baumwart R, Yamada N, Johnson E. Prevalence of Dirofilaria immitis antigen in client-owned pet dogs before and after serum heat treatment. In: Proceedings, Annual ACVIM Forum, vol. 30. Denver: CO. J Vet Intern Med; 2016. p. 1428. 
39. Zajac AM, Conboy GA. Detection of parasites in the blood. In: Veterinary Clinical Parasitology. 8th ed. Ames: Wiley-Blackwell; 2012. p. 185-211.

40. Peribanez MA, Lucientes J, Arce S, Morales M, Castillo JA, Gracia MJ. Histochemical differentiation of Dirofilaria immitis, Dirofilaria repens and Acanthocheilonema dracunculoides microfilariae by staining with a commercial kit, Leucognost-SP. Vet Parasitol. 2001;102:173-5.

41. Genchi C, Kramer LH, Rivasi F. Dirofilarial infections in Europe. Vector Borne Zoonotic Dis. 2011;10:1307-17.

42. Genchi C, Venco L, Genchi M. Guideline for the laboratory diagnosis of canine and feline Dirofilaria infections. Mappe Parassitologiche. 2005; 8:138-44.

43. Magnis J, Lorentz S, Guardone L, Grimm F, Magi M, Naucke T, et al. Morphometric analyses of canine blood microfilariae isolated by the Knott's test enables Dirofilaria immitis and D. repens species-specific and Acanthocheilonema (syn. Dipetalonema) genus-specific diagnosis. Parasit Vectors. 2013;6:48

44. Ciocan R, Darabus G, Igna V. Morphometric study of microfilariae of Dirofilaria spp. on dogs. Bull UASVM. Vet Med. 2010;67:45-9.

45. Taylor MA, Coop RL, Wall RL. Parasites of dogs and cats. In: Veterinary Parasitology. 4th ed. Ames, IA, USA: Blackwell Pub; 2016. p. 599-677.

46. Liotta JL, Sandhu GK, Rishniw M, Bowman DD. Differentiation of the microfilariae of Dirofilaria immitis and Dirofilaria repens in stained blood films. J Parasitol. 2013;99:421-5.

47. Rishniw M, Barr SC, Simpson KW, Frongillo MF, Franz M, Dominguez Alpizar $J$. Discrimination between six species of canine microfilariae by a single polymerase chain reaction. Vet Parasitol. 2006;135:303-14.

48. Rojas A, Rojas D, Montenegro VM, Baneth G. Detection of Dirofilaria immitis and other arthropod-borne filarioids by an HRM real-time qPCR, bloodconcentrating techniques and a serological assay in dogs from Costa Rica. Parasit Vectors. 2015:8:170

49. Schnyder M, Deplazes P. Cross-reactions of sera from dogs infected with Angiostrongylus vasorum in commercially available Dirofilaria immitis test kits. Parasit Vectors. 2012;5:258.

50. Aroch I, Rojas A, Slon P, Lavy E, Segev G, Baneth G. Serological crossreactivity of three commercial in-house immunoassays for detection of Dirofilaria immitis antigens with Spirocerca lupi in dogs with benign esophageal spirocercosis. Vet Parasitol. 2015;211:303-5.

51. Krucik DD, Van Bonn W, Johnson SP. Association between positive canine heartworm (Dirofilaria immitis) antigen results and presence of Acanthocheilonema odendhali microfilaria in California sea lions (Zalophus californianus). J Zoo Wildl Med. 2016;47:25-8.

52. Skinner D, Mitcham JR, Starkey LA, Noden BH, Fairbanks WS, Little SE. Prevalence of Babesia spp., Ehrlichia spp., and tick infestations in Oklahoma black bears (Ursus americanus). J Wildl Dis. 2017;53:781-7.

53. Venco L, Manzocchi S, Genchi M, Kramer LH. Heat treatment and falsepositive heartworm antigen testing in ex vivo parasites and dogs naturally infected by Dirofilaria repens and Angiostrongylus vasorum. Parasit Vectors. 2017;10:476

54. Diakou A, Kapantaidakis E, Tamvakis A, Giannakis V, Strus N. Dirofilaria infections in dogs in different areas of Greece. Parasit Vectors. 2016;9:508.

55. Matherne CM, Green SP, Corwin RM, Kelley ST. Detection of circulating Dirofilaria immitis antigens in random source laboratory dogs: evaluation of two commercial serodiagnostic tests. Lab Anim Sci. 1988;38:584-7.

56. Patton S, McCracken MD. Prevalence of Dirofilaria immitis in cats and dogs in eastern Tennessee. J Vet Diagn Invest. 1991:3:79-80.

57. Lee JC, Lee CY, Shin SS, Lee CG. A survey of canine heartworm infections among German shepherds in South Korea. Korean J Parasitol. 1996; 34:225-31.

58. Duran-Struuck R, Jost C, Hernandez AH. Dirofilaria immitis prevalence in a canine population in the Samana Peninsula (Dominican Republic) - June 2001. Vet Parasitol. 2005;133:323-7.

59. Starkey LA, Newton K, Brunker J, Crowdis K, Edourad EJP, Meneus P, et al. Prevalence of vector-borne pathogens in dogs from Haiti. Vet Parasitol. 2016;224:7-12

60. Agrolab, SpA: Filarchek. 2009. http://www.alphadia.be/en/files/Filarcheck validation R0-10-09-09.pdf. Accessed 1 Sept 2017.

61. Abaxis, Inc.: 888-9201 Rev. F. 2015. https://www.abaxis.com/sites/default/ files/resource-brochures/Rapid\%20Test\%20Kit.pdf. Accessed 1 Sept 2017.

62. Zoetis, Inc.: DiroChek ${ }^{\oplus}$ Heartworm Antigen Test Kit. 2016. https://www. zoetisus.com/products/diagnostics/dirochek-heartworm-antigen-test-kit.aspx. Accessed 1 Sept 2017
63. Zoetis, Inc.: Technical bulletin WIT-00130. 2016. https://www.zoetisus.com/ misc/files/pdfs/witness-heartworm-technical-bulletin.pdf. Accessed 1 Sept 2017.

64. McCall JW, Suprakorndej N, McCall SD, Mansour AE. Evaluation of feline heartworm antibody test kits and diagnostic laboratory tests. In: Soll MD editor. Recent Advances in Heartworm Disease Symposium '01. Batavia, Illinois: American Heartworm. Society. 2001:125-33.

65. IDEXX Laboratories, Inc:: Test accuracy. 2016. https://idexxcom-liveb02da1e51e754c9cb292133b-9c56c33.aldryn-media.com/filer_public/bf/d3/ bfd3ddd8-a353-456e-8e0e-42e22a7e9b73/snap-feline-triple-test-accuracy. pdf. Accessed 1 Sept 2017

66. Snyder PS, Levy JK, Salute ME, Gorman SP, Kubilis PS, Smail PW, et al. Performance of serologic tests used to detect heartworm infection in cats. Amer Vet Med Assoc. 2000;216:693-700.

67. Berdoulay P, Levy JK, Snyder PS, Pegelow MJ, Hooks JL, Tavares LM, et al. Comparison of serological tests for the detection of natural heartworm infection in cats. J Amer Anim Hosp Assoc. 2004;40:376-84.

68. Jacobs DE. Principles of veterinary parasitology. Chichester, West Sussex, UK, Hoboken. NJ, USA: John Wiley \& Sons, Ltd; 2016. p. 266-7.

69. Foreyt WJ. Veterinary parasitology: reference manual. 5th ed. Ames, lowa: lowa State University Press; 2001. p. 26.

70. Bowman DD. Georgis' Parasitology for Veterinarians. 10th ed. London: Elsevier Health Sciences; 2014. p. 346

\section{Submit your next manuscript to BioMed Central and we will help you at every step:}

- We accept pre-submission inquiries

- Our selector tool helps you to find the most relevant journal

- We provide round the clock customer support

- Convenient online submission

- Thorough peer review

- Inclusion in PubMed and all major indexing services

- Maximum visibility for your research

Submit your manuscript at www.biomedcentral.com/submit
) Biomed Central 